\title{
Antreja tribernik MANIPULACIJE NA OSEBNI RAVNI V MEDOSEBNIH ODNOSIH
}

\section{POVZETEK}

Manipulacija ni nikomur neznana in tuja. Vsi smo jo že kdaj doživeli in morda tudi kdaj povzročili. Napak je, če je ne prepoznamo, če jo opravičimo, predvsem pa, če se ne odločimo, da bomo spremenili svoje vedenje. Dlje časa trajajoča manipulacija pusti posledice na vseh udeležencih: žrtvi, opazovalcu in povzročitelju.

Manipulacija je odnos med ljudmi, v katerem niso upoštevane potrebe vseh udeležencev. Povezana je z izkoriščanjem in zavajanjem, z nehumanostjo in neetičnostjo, ki jo izraža manipulator v svojih dejanjih na poti do uspeha, samopotrjevanja in za dosego svojega cilja. Pri manipulaciji se zrušijo meje drugega, saj povzročitelj vsili potrditev svoje nadvlade in podrejenost žrtve.

Manipulator posega v osebno integriteto žrtve in omejuje njen potencial. Žrtev izolira, nadzira in zastrašuje, izdela cel sistem, da žrtev ulovi v svojo mrežo in posesa kot pajek. Pri najuspešnejši manipulaciji drug udeleženec manipulacije ne prepozna in je srečen, da lahko sodeluje z manipulatorjem, saj si domišlja, da je cilj drugega tudi njegov cilj. Zato pravimo, da manipulator ukrade manipuliranemu dušo.

Ključne besede: medosebni odnosi, manipulacije, komunikacija

\section{INTERPERSONAL RELATIONSHIP MANIPULATION AT A PERSONAL LEVEL - ABSTRACT}

Manipulation is not unknown or strange to any of us. We have all experienced it, or perhaps even practiced it. It is wrong not to recognize it, to find excuses for it, and, above all, it is wrong not to decide to change one's behaviour. Long-lasting use of manipulation leaves consequences on all the parties involved: the victim, the observer and the perpetrator.

Manipulation is a relation between persons which does not consider the needs of everybody involved. It means exploitation and misleading, inhumane and unethical behaviour on the part of the manipulator, which he uses in order gain success, self-confirmation and to achieve his goals. In the act of manipulation personal boundaries of the other person are violated since the manipulator enforces his dominance and subjectedness of the victim.

The manipulator invades the victim's personal integrity, limiting their potential. He isolates, controls and intimidates them; by devises a system to catch the victims, to entangle them in his net and suck them up like a spider. If the manipulation is very successful, the other person does not recognize it as such; they consider themselves happy to be cooperating with the manipulator, as they identify his goals as their own. Therefore, the manipulator can be said to have stolen the manipulated person's soul.

Keywords: interpersonal relationship, manipulation, communication

Manipulacijo bomo obravnavali kot vrsto medosebnih odnosov med prijatelji, sodelavci ali člani družine ali na zelo osebni ravni. Posebno razpravo bi zaslužile manipulacije v javnosti, te postajajo vedno pogostejše in se razraščajo v gospodarstvo, politične odnose in poslovna razmerja. Spoznanja o manipulaciji na osebni ravni nam lahko pomagajo, da prepoznamo in se laže obranimo pred vse pogo- stejšimi manipulacijami $\mathrm{v}$ javnosti. Bistvo odnosa manipulacije, zaslepitev in zloraba žrtve, ostaja enako.

Manipulacija ni nikomur neznana in tuja. Vsi smo jo že kdaj doživeli in morda tudi kdaj povzročili. Nevarno in napak je, če je ne prepoznamo, če jo spregledamo, če jo opravičimo, predvsem pa, če se ne odločimo, da bomo spremenili svoje vedenje. Dlje časa trajajoča 
manipulacija pusti posledice na vseh udeležencih: žrtvi, opazovalcu in povzročitelju. Manipulacija nastane v odnosu med ljudmi.

\section{ODNOSI MED LJUDMI}

Odnos je sprejemanje in oddajanje sporočil. Za odnos sta potrebna dva človeka.

Vsak odnos je krožen, je serija povezanih reakcij. Mi v sogovorniku sprožimo odgovor in obratno.

Odnos JAZ-TI je odnos medsebojne uporabe, ki daje možnost izražanja obema udeležencema. V odnosu moraš videti potrebe sogovornika. Samo tak odnos je lahko kakovosten in trajen, saj zadovoljuje čustvene potrebe obeh udeležencev, zaradi česar se vanj rada vračata in ga poglabljata.

V odnosu JAZ-ONO je drugi pol popredmeten in $\mathrm{v}$ odnosu ni upoštevan. Tak odnos ni trajen. Če v odnosu uporabnika nista enakopravna, eden doživlja neugodje in se takega odnosa izogiba. Odnos, kjer je vodilen le eden od udeležencev in tega ni mogoče spremeniti, je treba prekiniti, sicer pride do zlorabe.

\section{SPOROČILA MED LJUDMI}

Odnos je sestavljen iz sporočil. Abecede sporočil se učimo od rojstva dalje. Sprva dojenček sporoča le z glasovi, ki izražajo ugodje ali neugodje, kasneje pa sporočila oddajamo na verbalen in neverbalen način.

Verbalna sporočila gredo skozi socialno kontrolo in so cenzurirana. Sporočila povemo tako, kot to pričakuje naša okolica, ker je to eden od preživetvenih mehanizmov.

Neverbalna sporočila so iskrena in pristna, sprejemamo jih prek čustvenih vtisov.

Zanimivo je, da raje sledimo verbalnemu sporočilu kot neverbalnemu.

Verbalna in neverbalna sporočila se nikdar popolnoma ne ujemajo. Če je razhajanje med verbalnimi in neverbalnimi sporočili veliko, taka komunikacija ni iskrena.

\section{MANIPULACIJA}

Kadar posameznik $\mathrm{v}$ transakciji ne upošteva potreb drugega in poskuša prikrito doseči samo svoj cilj, svojo korist, govorimo o manipulaciji. Glede na ego stanje udeleženčevih vprašanj in odgovorov so transakcije lahko:

- komplementarne: te transakcije niso konfliktne. Oba udeleženca sta lahko v ego stanju odraslega (npr. zdravnik in medicinska sestra med vizito) ali oba v ego stanju otroka (npr. otroci med igro);

- križne: te transakcije so bolj

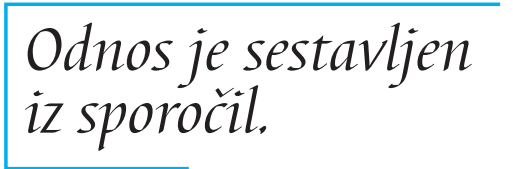
zapletene in pogosto privedejo do prekinitve komunikacije. O njih govorimo, kadar je nekdo v ego stanju odraslega in drugi v ego stanju otroka (npr. delodajalec - delavec);

- prikrite: te transakcije so zelo zapletene, $\mathrm{v}$ njih se prepleta več ego stanj udeležencev in pogosto vodijo do zlorab (v manipulacijo). Npr. zavarovalničar želi skleniti zavarovanje in reče stranki: »To zavarovanje je najboljše, vendar je drago in prepričan sem, da si ga ne morete privoščiti.«; stranka na to lahko odvrne: »Prav to zavarovanje bom sklenil.«Prvi udeleženec se z dvema trditvama svojega ego stanja odraslega obrača na odraslo in otroško ego stanje stranke. Sledi mu odgovor v ego stanju otroka, kar je natanko to, kar je želel. Berne poudarja, da je vsaka »igra $\ll$ v bistvu nepoštena, posledice pa so hude. Zanj je manipulacija nepoštena, egoistična, usmerjena v lastno korist in ne upošteva koristi drugih. Pri manipulaciji se zrušijo meje drugega, saj povzročitelj vsili potrditev svoje nadvlade in podrejenost žrtve.

Manipulacija je sestavljena iz skritih transakcij, ki vodijo $\mathrm{k}$ vnaprej določenemu in premišljeno izbranemu cilju. $\mathrm{V}$ njih se skrivajo pasti, ki vodijo k cilju, ki je vedno koristen za tistega, ki »igro « (prikrito komunikacijo) vodi. 
Manipulator prikriva, kaj namerava, prikriva pravila, poteze vleče premišljeno in ne razkrije cilja oz. namena.

Manipulacij ali zlorab se lahko zavedamo ali se jih ne zavedamo. Vedno pa izhajajo iz potreb tistega, ki jih izzove. Pri manipulaciji so zanikane potrebe drugega, da manipulator doseže svoj cilj. Gre za odnos JAZ-ONO, kjer je Manipulatorji so kronični lažnivci. drugi udeleženec popredmeten in služi le za dosego cilja. Pri najuspešnejši manipulaciji drugi udeleženec zlorabe ne prepozna in je srečen, da lahko sodeluje v igri, saj si domišlja, da je cilj drugega tudi njegov cilj. Zato pravimo, da manipulator ukrade manipuliranemu dušo. Manipulirani se ravna po vrednotah drugega in ne loči svojih potreb od potreb drugega. Manipulacijo želimo prepoznati zato, da ugotovimo, ali nas kdo izrablja, saj želimo imeti čim več pristnih odnosov.

\section{KAKO MANIPULATOR DOSEŽE SVOJ CILJ}

Najpomembnejši inštrument manipulatorja je jezik, saj je zavestna uporaba jezika z določenim ciljem prvi pogoj za uspešno vplivanje na ljudi. Manipulator nadzoruje tudi govorico telesa. Kadar želi manipulator v pogovoru prepričati nasprotnika, $v$ središče manipulativne igre ne bo postavil sebe, ampak svojega nasprotnika. Manipulator uporablja tangentne komunikacije in plastična sporočila (recimo vprašaš, kakšno

Manipulator rad dela razprtije, ker s tem druge osami in oslabi. Igra na vse karte: po potrebi zna odigrati vlogo žrtve, govori o bolezni in lastnih stiskah ter tako pritegne pozornost in zaščito, spremeni tok dogajanja, če vidi, da se oddaljuje od cilja ... Izdela cel sistem, da žrtev ulovi v svojo mrežo in jo posesa kot pajek. Druge posluša le navidezno, vse presliši, tuji problem se ga ne dotakne in ga ne odvrne od lastnega cilja. bo jutri vreme, on odgovori »vedno se toplo oblečem«). Manipulator druge krivi za nastalo situacijo, s tem vceplja svoja pravila in uveljavlja svoje potrebe.

Vedno išče napake drugih, s čimer poveča njihovo ranljivost in krepi občutek krivde pri njih. Manipulator ne izraža čustev, nikdar ne pove, kaj misli in kaj namerava, zato žrtev ne pripravi obrambe. Manipulator zavrnitve nikoli ne izrazi direktno. Pri drugih išče popolnost, ker tako laže očita napake (denimo »ti bi pa moral vedeti ...«). Zmanjšuje tudi vrline drugih (recimo nekdo nekoga pohvali, on pa odgovori »na oddelku je v redu, je pa zadnjič slabo vodil sestanek $\mathrm{z}$ investitorji $\ll)$.

Manipulator se pogosto izkazuje s spoštovanjem splošno znanih družbenih norm in človekoljubjem, nečim, kar je na očeh (denimo podpre otroke $\mathrm{v}$ Afriki). Pogosto na prikrit način grozi. Vzbuja občutek, da veliko ve, zato navaja podatke iz zemljepisa, zgodovine ..., lahko tudi nepreverjene in napačne. Pri tem se zelo zanaša na zaupanje in nevednost drugih; če ga razkriješ, te sovraži.

Manipulatorji so kronični lažnivci in prikrojijo realnost po lastni potrebi; če jim dokažeš laž, se vedno izvijejo in se spretno izmaknejo soočenju iz oči v oči. Manipulator tipa teren, da bi ugotovil, kaj bi drugi želeli, in jim to tudi obljublja, čeprav svojih obljub ne izpolni. Vedno skrbi le zase in svoje potrebe, pogosto vidno uživa ob nesreči drugih. Značilnost manipulatorja je egocentrizem; tega v otroštvu ni izživel in ga je podaljšal v odraslo dobo.

Manipulator je zelo zaposlen sam s seboj in se počuti ogroženega.

\section{KAKO PREPOZNAMO MANIPULATORJA (LASTNOSTI)}

Manipulator je zelo ljubosumen in žrtvi ne dopušča stikov s prijatelji in sorodniki, želi jo osamiti, ker s tem zmanjša vpliv drugih. Ne prenese, da mu natočimo čistega vina, zato je soočenje z njim nemogoče. Druge posluša le 
navidezno, ko mu žrtev pripoveduje o svojih pravicah, potrebah in željah, se obrne stran, začne zehati in na neverbalen način pove, da ga to ne zanima ..., si zaželi limonade.

Manipulator žrtvi nalaga naloge, ki jih kombinira s presenečenjem in daje napotke zadnji trenutek, s tem ima vedno on boljši položaj. Pazi, da vedno govori logično, sklicuje se na prejšnje izjave, dokazuje poučenost in da je vreden zaupanja (njegove navedbe niso vedno točne ..., govori le za vtis in blefira).

Če je treba, zna tudi laskati, prinaša darila, občasno izrazi skrb za žrtev, ki jo s tem naredi negotovo. Sledi načelu zmagam-zgubiš. In tako uspešno dosega cilje.

Manipulator pripelje žrtev do tega, da dela za njegove cilje stvari, ki jih drugače ne bi. Žrtev tako obremeni, da vedno misli nanj in je z njim obsedena.

Vse napelje tako, da vedno jemlje in ne daje, dajanje ga moti, ogroža. Če daje darila, dela to običajno le v situacijah, ko svojo manipulacijo v odnosu z novo osebo šele uveljavlja. Zato, da »omami« svojo žrtev, poklanja darila tudi manipulator, ki navadno velja za skopuha in bi pri njem bolj težko odkrili kako radodarnost v običajnih situacijah.

Pozitiven manipulator je v življenjskem položaju kralja in nalaga naloge, lahko pa je v negativnem položaju in ljudi izkorišča za dosego svojih ciljev. Manipulator sebe doživlja kot središče pozornosti, je v ego stanju otroka ali roditelja. Predvsem je ogrožen in ima premalo samoza-

Žrtev manipulacije pa lahko postane tudi zrel, samozavesten človek. Ta v življenju pričakuje recipročnost, $\mathrm{v}$ komunikaciji je direkten in tako komunikacijo pričakuje tudi od drugih. Ne išče dvojnega pomena besed in s tem manipulatorju olajša delo. Seveda pa bo žrtev z razvitim ego stanjem odraslega kmalu prepoznala manipulacijo in se osvobodila. Razvito ego stanje odraslega nam daje svobodo in vzpostavlja dobre odnose. vesti, da bi jasno nastopil ali verjel, da mu bo uspelo brez drugih. Zaradi stalne ogroženosti in strahov ljudi zelo potrebuje. Uporablja človeka v odnosu s človekom kot naraven proces med družbenimi bitji, ljudi zlorablja za svoje potrebe.

\section{KDO SO LAHKO ŽRTVE MANIPULATORJA}

Največ manipulacij se dogaja med osebami, ki se med seboj poznajo, v družinskih oz. partnerskih odnosih in na delovnem mestu.

Žrtve manipulacije so pogosto ranjeni, preobčutljivi ljudje, pri katerih manipulator zaigra na struno odgovornosti.

Manipulaciji najlaže podležejo nevedni ljudje, manj razvite osebnosti, ki se počutijo nelagodno, če se morajo sami odločati, in ljudje, ki radi posnemajo druge ali iščejo zaščito.

Predmet manipulacije so tudi ljudje z nizko samozavestjo, ki imajo slabo razvite obrambne mehanizme in se pustijo voditi. To so hiperzaščiteni otroci, ki ne znajo izraziti in braniti svojih interesov in potreb.

Ljudje z življenjskim scenarijem žrtve so lahek plen, saj so jim že starši govorili »ti potrpi ..., ti počakaj ...«.

Žrtve so tudi ljudje s čustvenim primanjkljajem in ki jih je strah. Vsak človek si mora oblikovati svoje cilje, drugače pristopi manipulator in pokaže svoj cilj.

$\mathrm{V}$ tej kategoriji so tudi mladi upokojenci, ki se jim je spremenil tok življenja in so izgubili svoje socialno okolje. Nov vzorec jim izdelajo drugi mladi po svojih potrebah. Če se temu uprejo, okolica v njih vzbudi občutek krivde in slednjič popustijo, ker jim mladi obljubijo družbo, oni pa se bojijo biti sami.

\section{KAKO LAHKO POMAGAMO ŽRTVI}

Žrtev manipulacijo težko prepozna, ker manipulator ne vstopa v konflikt. Ker ni konflikta, se pri žrtvi obrambni mehanizem ne aktivira. 
Manipulator žrtev drži trdno v rokah, da ne prisluhne svojim čustvenim nagibom in potrebam. Žrtev sprejme manipulatorjeve potrebe in se $s$ tem ne zaveda manipulacije. Postane njegova podaljšana roka.

Manipulator posega $\mathrm{v}$ osebno integriteto žrtve in omejuje njen potencial. Žrtev izolira, nadzira in zastrašuje. To pogosto počne pod krinko »ker ti hočem dobro«. Žrtvi Pozitivna manipulacija ne obstaja. sporoča, da je manjvredna ali sploh ničvredna, in žrtev začne temu sporočilu verjeti.

Čez čas postane manipulirana oseba negotova in zaskrbljena. Vse bolj je nemirna, živčna, zmedena, napeta, izraža utrujenost, je demotivirana, nič je ne pretrese in ne navduši, je brezbrižna do vsega sveta, ker je tako obremenjena $\mathrm{z}$ delom za manipulatorja. Končno zboli in postane agresivna. Pesti jo nespečnost, pojavijo se prebavne in kožne težave, težave z želodcem in zbranostjo ... Ob tem manipulatorju moč raste. Žrtev izgublja identiteto, postane nezanesljiva in nepredvidljiva, za delovanje zdaj že sama potrebuje manipulatorja. Od zunaj manipulacijo hitro vidimo, žrtev pa je ne prepozna in jo težko sprejme. Manipulacija ostane dolgo skrita, ker storilec najde učinkovita sredstva, da jo ohranja v tajnosti. Če hočemo žrtvi pomagati, ji moramo odkriti manipulatorja in njegov cilj. Žrtev manipulatorja brani, zato ji moramo na primeru dokazati, da deluje proti svoji volji. Žrtvi z vprašanji ozavestimo položaj (recimo kako pa ti misliš ..., kako bi pa ti rad ...). Žrtvi moramo odkriti tehniko manipulatorjevega odnosa $\mathrm{z}$ njo. Počasi začne razbirati, kaj se dogaja, pride do dvoma, zaupanje do manipulatorja upada, žrtev opazuje, ali ima manipulator res cilj, ki zadovolji le njegove interese ...

Ob spremembi vedenja žrtve se manipulator brani in takoj spremeni taktiko, sprva postane do žrtve pozoren, če se mu zdi, da jo izgublja, ji naprti velik občutek krivde.

Rešitelj mora občutek krivde zmanjševati in žrtvi pomagati dvigniti samozavest. To se doseže s pohvalo. Pohvala mora biti upravičena, saj žrtev sprva pohvalo zavrača. Pri žrtvi moramo prebuditi stare vrednote (npr. ali si vedno tako mislil ..., ali ne bi ti včasih naredil drugače ...). Žrtev naj bi se naučila sama preverjati dvojni pomen manipulatorjevih sporočil. S tem utrdi ego stanje odraslega in ponovno začne sama odločati.

Cilj uspešnega reševanja žrtve je, da izmaknemo manipulatorju nam drage ljudi. Naš namen ni sneti masko manipulatorju, saj je potem eksistenčno ogrožen, ker ne zna drugače živeti. Manipulatorju lahko pomaga le psihoterapevt, ki mu nevtralizira otroštvo in zgradi nov odnos do sveta (pet let terapije).

\section{ZAKLJUČEK}

Iz tega sledi, da pozitivna manipulacija ne obstaja, čeprav se tako rada omenja pri vzgoji otrok, na delovnem mestu, pri mediaciji ... Manipulacija je namreč odnos med ljudmi, ki je povezan z izkoriščanjem in zavajanjem, $\mathrm{z}$ nehumanostjo in neetičnostjo, ki jo izraža posameznik ali skupina ljudi v svojih dejanjih na poti do uspeha, samopotrjevanja in za dosego svojega cilja.

Pogoste so manipulacije s čustvi ljudi v medijih in za reklamne namene. Le ljudje $\mathrm{z}$ močno intuicijo (10 odstotkov ljudi) preverjajo posredovano informacijo in pomislijo, da morda ni pravilna. Ti ljudje se manipulaciji že na začetku uprejo.

Značilnost manipulatorja je egocentrizem, ki ni bil izživet $\mathrm{v}$ otroštvu in ga je posameznik podaljšal v odraslo dobo. Manipulator vedno

Največ manipulacij se dogaja med osebami, ki se poznajo, v družinskih oziroma partnerskih odnosih in na delovnem mestu. Žrtve manipulacije so najpogosteje ranljivi, preobčutljivi ljudje s čustvenim primanjkljajem in nizko samozavestjo. To so ljudje, ki ne znajo izraziti in braniti svojih interesov in potreb. 
skrbi le zase in za svoje potrebe, zelo je zaposlen sam s seboj in se počuti ogroženega. Sebe doživlja kot središče pozornosti in je v ego stanju otroka ali kritičnega roditelja.

Manipulacijo želimo prepoznati, ker si želimo čim več pristnih in kakovostnih odnosov, ki nam omogočajo uravnoteženo, zadovoljno in zdravo življenje. Pred manipulacijo se branimo z utrjevanjem samozavesti, krepitvijo pozitivne samopodobe in razvijanjem ego stanja odraslega. Razvito močno ego stanje odraslega nam daje svobodo in vzpostavlja dobre medsebojne odnose.

\section{LITERATURA}

Berne, E. (2007). Katero igro igraš? Ljubljana: Sinesis.

Brajša, P. (1978). Splošna psihodinamika samoupravnega vedenja. Ljubljana: Delavska enotnost.

Kirschner, J (1994). Umetnost manipulacije - Osem zakonov vplivanja na ljudi. Ljubljana: DZS. 